\title{
Pathogenesis and management of Kawasaki disease
}

\author{
Anne H Rowley, $\mathrm{MD}^{\dagger}$ and \\ Northwestern University Feinberg School of Medicine, Pediatrics, Morton 4-685B, 310 E Superior \\ St, Chicago, IL 60611, USA, Fax: +1312503 1181 \\ Stanford T Shulman, MD \\ The Division of Infectious Diseases, The Children's Memorial Hospital, 2300 Children's Plaza \#20, \\ Chicago, IL 60614, USA, Tel.: +1 773880 4187, Fax: +1 7738808226
}

Anne H Rowley: a-rowley@northwestern.edu; Stanford T Shulman: sshulman@northwestern.edu

\begin{abstract}
Kawasaki disease (KD) is an acute systemic inflammatory illness of young children that can result in coronary artery aneurysms, myocardial infarction and sudden death in previously healthy children. Clinical and epidemiologic features support an infectious cause, but the etiology remains unknown four decades after KD was first identified by Tomisaku Kawasaki. Finding the cause of KD is a pediatric research priority. We review the unique immunopathology of KD and describe the current treatment. New research has led to identification of viral-like cytoplasmic inclusion bodies in acute KD tissues; this finding could lead to identification of the elusive etiologic agent and result in significant advances in KD diagnosis and treatment. Current management of acute KD is based upon prospective, multicenter treatment trials of intravenous immunoglobulin (IVIG) with high-dose aspirin. Optimal therapy is $2 \mathrm{~g} / \mathrm{kg}$ IVIG with high-dose aspirin as soon as possible after diagnosis during the acute febrile phase of illness, followed by low-dose aspirin until follow-up echocardiograms indicate a lack of coronary abnormalities. The addition of one dose of intravenous pulse steroid has not been shown to be beneficial. For the 10-15\% of patients with refractory KD, few controlled data are available. Options include repeat IVIG (our preference), a 3-day course of intravenous pulse methylprednisolone, or infliximab $\left(\operatorname{Remicade}^{\circledR}\right)$. Patients with mild-to-moderate coronary abnormalities should receive an antiplatelet agent such as low-dose aspirin (3-5 mg/kg/ day) or clopidogrel ( $1 \mathrm{mg} / \mathrm{kg} /$ day up to $75 \mathrm{mg}$ ), and those with giant ( $\sim 8 \mathrm{~mm}$ diameter) or multiple coronary aneurysms should receive an antiplatelet agent with an anticoagulant such as warfarin or low-molecular-weight heparin. Acute coronary obstruction requires acute thrombolytic therapy with a surgical or percutaneous interventional procedure.
\end{abstract}

\section{Keywords}

coronary artery aneurysms; cytoplasmic inclusion bodies; IgA immune response; IgA plasma cells; inclusion bodies; intravenous immunoglobulin; Kawasaki disease; synthetic antibodies; vasculitis

\footnotetext{
$\dagger$ Author for correspondence: Northwestern University, Feinberg School of Medicine, Pediatrics, Morton 4-685B, 310 E Superior St, Chicago, IL 60611, USA, Fax: +1 312503 1181, a-rowley@northwestern.edu.

For reprint orders, please contact reprints@expert-reviews.com

Financial \& competing interests disclosure

Anne H Rowley is supported by National Institutes of Health grant HL63771 and the Kawasaki Disease Fund of the Children's Memorial Hospital. The authors have no other relevant affiliations or financial involvement with any organization or entity with a financial interest in or financial conflict with the subject matter or materials discussed in the manuscript apart from those disclosed.

No writing assistance was utilized in the production of this manuscript.
} 
Kawasaki disease (KD) is the most prevalent cause of acquired heart disease in children in industrialized nations. It usually affects previously healthy children, who may develop coronary artery aneurysms, myocardial infarction and sudden death as a result of the illness. The etiology of KD remains a major pediatric enigma, despite efforts to identify the cause over the last four decades. The scope of this article is to review the unique immunopathology of KD and to describe current treatment, which is primarily aimed at blocking or reducing inflammation in the coronary arteries. We detail the evidence in support of an infectious cause of $\mathrm{KD}$, and we describe exciting new research that has led to discovery of viral-like cytoplasmic inclusion bodies in acute KD tissues; it is hoped that this finding will lead to the identification of the causative agent and to improved diagnostic and treatment modalities. In addition, we update treatment recommendations for patients with $\mathrm{KD}$ and its complications.

\section{KD is an acute systemic inflammatory process of young childhood}

Kawasaki disease is a systemic inflammatory process that predominately affects children 6 months to 5 years of age, although younger infants and older children can also develop the illness. Autopsy studies of fatal cases have clearly demonstrated that inflammation occurs in multiple organs and tissues in KD [1], although inflammation of the coronary arteries is the most clinically significant aspect of the illness. The cardiovascular, respiratory, gastrointestinal, dermatologic, urinary, nervous and lymphoreticular systems can all be involved [1]. Some theories of KD pathogenesis focus upon endothelial cell antigens as the exclusive targets of the disease process, but such models do not explain many of the pathologic findings of KD such as bronchitis, prostatitis and pancreatic ductitis. Since the clinical and epidemiologic features of KD support an infectious cause, one speculation is that the infectious agent travels from its portal of entry through the bloodstream and infects many organs and tissues, with the immune response targeting these sites of infection. The theory of KD etiology that best fits the available data is that a ubiquitous infectious agent results in asymptomatic infection in most individuals but causes $\mathrm{KD}$ in a subset of genetically predisposed individuals [2].

\section{Inflammatory cell infiltrate in acute KD tissues provides clues to disease pathogenesis}

Although neutrophils are the predominant inflammatory cell type in the peripheral blood in acute $\mathrm{KD}$, they are not the predominant cell type in the inflammatory infiltrate in KD tissues [1]. Inflamed tissues in acute KD show large mononuclear cells, lymphocytes, macrophages and plasma cells, with a smaller number of neutrophils [1,3-5]. CD8 T lymphocytes have been found to predominate over CD4 T lymphocytes in the inflamed arterial wall [3], which is consistent with an immune response to an intracellular pathogen. Activated myeloid dendritic cells are present and colocalize with CD3 T lymphocytes [6]. We showed that although IgG and IgM plasma cells are evident in the arterial wall, IgA plasma cells predominate [4,5]. The presence of a predominant IgA plasma cell response in a non-lymphoid, non-mucosal tissue such as arterial tissue is distinctly unusual. The presence of $\operatorname{IgA}$ deposits or $\operatorname{Ig} \mathrm{A}$ immune complexes in the skin or kidney is characteristic of Henoch-Schönlein purpura and IgA nephropathy, but IgA plasma cells are not observed in these tissues in these diseases. Such a prevalent IgA plasma cell response as seen in the acute stage of KD suggested stimulation of the immune system at a mucosal site, with switch of B lymphocytes to IgA. Our further studies indicated a marked $\operatorname{IgA}$ plasma cell response in the respiratory tract in acute $\mathrm{KD}$, with $\operatorname{IgA}$ plasma cell infiltration of additional inflamed KD tissues such as the kidney and pancreas [5]. The pattern of an IgA B lymphocyte and a CD8 T-lymphocyte response is consistent with an adaptive immune response to an intracellular pathogen such as a virus entering at a mucosal site [3]. 


\section{Inflammatory cells in the KD arterial wall secrete cytokines \& enzymes that result in damage to the vessel}

As would be expected in any illness associated with prolonged fever and multiorgan system inflammation, many cytokines are upregulated in the peripheral blood in acute KD [7-9]. In addition, macrophages, $\mathrm{T}$ lymphocytes and myofibroblasts secrete VEGF, matrix metalloproteinases, and other cytokines and enzymes within the arterial wall [10,11]. Secreted enzymes destroy collagen and elastin fibers, and the structural support of the arterial wall weakens, resulting in dilatation or aneurysm formation. Angiogenesis ensues, with neovascularization, the development of small blood vessels within the damaged arterial wall [12]. These new blood vessels secrete E-selectin and VCAM 1, and may serve to potentiate inflammatory cell infiltration by promoting endothelial cell interactions with circulating inflammatory cells [13]. Damage to the arterial wall is patchy, with normal areas adjacent to severely inflamed areas even along the course of the same artery, which is more consistent with an inflammatory reaction to localized areas of infection than with widespread targeting of a human endothelial cell antigen.

\section{IgA response in acute $K D$ is antigen-driven \& the antigen resides in cytoplasmic inclusion bodies in KD tissues}

The presence of a marked IgA plasma cell response in acute $\mathrm{KD}$ tissues suggested a specific immune response, potentially directed at antigens involved in disease pathogenesis, such as an inciting etiologic agent. Because antigen-driven B-lymphocyte responses are oligoclonal, restricted to specific epitopes of the antigenic target, we performed studies to determine the clonality of the IgA response in acute KD. Analysis of gene sequences in the CDR3 region of the IgA plasma cells in the acute KD arterial wall revealed a strikingly oligoclonal response, with additional features of an antigen-driven process, such as somatic mutation, apparent among the sequences [14]. The presence of an oligoclonal IgA immune response provided us with the opportunity to prepare synthetic versions of the most prevalent $\operatorname{IgA}$ antibodies in the $\mathrm{KD}$ arterial wall. The goal of these studies was to identify antigenic targets of the KD IgA antibodies prevalent in acute KD tissues. Synthetic KD antibodies were used in immunohistochemistry experiments on acute KD and control tissues. These studies revealed the presence of a specific antigen in acute KD bronchial epithelium and in macrophages within inflamed KD tissues [15]. We detected the antigen in bronchial epithelium in ten out of 13 patients with acute KD but in none of nine control infants, and in coronary artery aneurysms in nine out of 12 acute KD and none out of ten control coronary arteries [15]. A panel of monoclonal synthetic KD antibodies was developed from KD IgA antibodies, and those that bound to KD tissues identified the same antigen in all cases, despite the difference in primary sequence of the antibodies, confirming the presence of an antigen-driven IgA immune response in the acute stage of KD. We found that synthetic antibodies made from IgA sequences that were more prevalent in $\mathrm{KD}$ arterial tissues showed stronger binding to acute $\mathrm{KD}$ tissues than those made from less prevalent sequences [16].

Using light and electron microscopy, we further studied the antigen identified by the synthetic $\mathrm{KD}$ antibodies. These studies showed that the antigen in acute KD bronchial epithelium is present in cytoplasmic inclusion bodies that are consistent with aggregates of viral proteins and nucleic acids [17]. Additional studies indicate that KD cytoplasmic inclusion bodies contain RNA but not DNA, and that they can be identified in $85 \%$ of acute and late-stage KD fatalities and $25 \%$ of adult controls, suggesting that the $\mathrm{KD}$ agent is a previously unidentified, ubiquitous RNA virus that can result in persistent infection [18]. 
Thus, all available data indicate that IgA antibodies in KD are targeting a microbial antigen, not an autoantigen.

\section{Genetic factors influence susceptibility to KD}

Asian children, particularly those of Japanese, Chinese and Korean ethnicity, have the highest incidence of $\mathrm{KD}$, but all racial and ethnic groups are affected. Incidence rates of KD in Japanese children are approximately tenfold higher than those in Caucasian children [19,20], and this higher incidence holds true for Japanese children living a Western lifestyle in the USA [19], strongly supporting a genetic predisposition for KD. The molecular genetics of KD is an emerging field [21]. Genomewide linkage analysis has provided potential loci of susceptibility to KD [22]; such studies led to identification of ITPKC, a negative regulator of T-cell activation, as a gene associated with KD susceptibility and an increased risk of coronary artery lesions in both Japanese and American children [23]. Additional candidate genes potentially related to inflammation, apoptosis and cardiovascular pathology have recently been identified [24].

Susceptibility to KD is highly likely to be polygenic, and additional genes conferring susceptibility to KD will be undoubtedly identified over time.

\section{Management of KD}

\section{Acute-stage therapy}

Even though the precise etiology and pathogenesis of KD are incompletely understood, current management of acute KD is based upon prospective, controlled, multicenter treatment trials that clearly demonstrated the efficacy of intravenous immunoglobulin (IVIG) and high-dose aspirin to halt inflammation and to reduce the likelihood of the development of coronary abnormalities when administered by the tenth day of illness [25,26]. Initial studies demonstrated the efficacy of IVIG when given in four-to-five daily doses [27]. Follow-up trials clearly established the superiority of single high-dose IVIG ( $2 \mathrm{~g} / \mathrm{kg}$ given over 10-12 h) in combination with high-dose aspirin ( $80-100 \mathrm{mg} / \mathrm{kg} / \mathrm{day}$ in four divided doses) to normalize acute-phase reactants and achieve defervescence [28]. It is commonly believed that Asian children experience excessive toxicity when $80-100 \mathrm{mg} / \mathrm{kg} /$ day aspirin is used, and $30-50 \mathrm{mg} /$ $\mathrm{kg} / \mathrm{day}$ dosing is commonly used in Asia. Patients should be treated by the tenth illness day when possible because very few data exist regarding therapy later than the tenth day. While patients treated later than the tenth day often benefit from therapy clinically, the ability of treatment to prevent the development of coronary changes in this situation is much less certain.

It is unclear whether IVIG and aspirin treatment of KD patients instituted earlier than the fifth illness day leads to poorer outcomes, with different patient series reaching different conclusions [27-29]. It is likely that children diagnosed and treated before the fifth day have more severe $\mathrm{KD}$ than those who present later for care. A meta-analysis of all Japanese and North American IVIG trials showed that coronary outcome correlates directly with the total dose per kg of IVIG administered and confirmed that total IVIG doses less than $2 \mathrm{~g} / \mathrm{kg}$ are less effective in KD [30]. Coronary outcome was independent of the initial dose of aspirin administered (30-50 or $80-100 \mathrm{mg} / \mathrm{kg} / \mathrm{day})$.

Patients should undergo a baseline echocardiogram early in their hospitalization, and should remain in hospital until they have been afebrile and stable for at least $24 \mathrm{~h}$ to ensure that they do not need retreatment [31].

Adding corticosteroid therapy to IVIG and aspirin for primary therapy has not been clearly shown to be beneficial. Japanese trial findings must be interpreted cautiously because the IVIG and the aspirin regimens that were utilized differ from those used in the USA and because echocardiograms were not interpreted in a blinded fashion $[32,33]$. The most definitive trial in 
this regard showed no benefit of the addition of one dose of intravenous methylprednisolone (30 $\mathrm{mg} / \mathrm{kg}$ ) to the standard $2 \mathrm{~g} / \mathrm{kg}$ IVIG and $80-100 \mathrm{mg} / \mathrm{kg} /$ day aspirin regimen used in the USA, with the possible exception of the subgroup of patients who failed standard therapy and needed retreatment [34]. The latter observation will require further study.

\section{Rescue therapy for treatment failures}

Approximately $85-95 \%$ of patients treated with IVIG and aspirin respond promptly with defervescence and subsidence of inflammatory manifestations within $48 \mathrm{~h}$ of the conclusion of the IVIG infusion [25]. However, a subgroup of approximately 5-15\% fails to manifest an excellent clinical response, with persistent fever or only transient improvement with recurrent fever and inflammatory signs. The laboratory correlate is a rising or persistently elevated serum C-reactive protein level. Note that the erythrocyte sedimentation rate cannot be used to follow the degree of inflammation after IVIG has been administered, as it is artifactually elevated following IVIG. In these patients, the diagnosis of KD should be reassessed, as some of these patients may not actually have KD. In those patients who are confirmed to have KD, additional anti-inflammatory therapy is needed.

In these patients, a second $2 \mathrm{~g} / \mathrm{kg}$ dose of IVIG is generally effective in controlling disease activity. Up to $70-80 \%$ of nonresponders become afebrile, lose inflammatory signs and show decreased serum C-reactive protein values after a second dose of IVIG [35,36]. Some recommend a 3-day course of intravenous pulse methylprednisolone $(30 \mathrm{mg} / \mathrm{kg} / \mathrm{dose})$ rather than a second dose of IVIG, but we prefer to utilize pulse methylprednisolone in patients who have failed two $2 \mathrm{~g} / \mathrm{kg}$ doses of IVIG. In a very small number of particularly refractory patients, we have employed a slow oral steroid taper over several months once fever has resolved and the C-reactive protein levels have decreased substantially.

Another treatment modality for IVIG-refractory KD is infliximab (Remicade ${ }^{\circledR}$, Centocor, PA, USA), a chimeric mouse-human monoclonal antibody directed at soluble and membranebound TNF- $\alpha$. Use of this agent has been reported in an open-label study [37] and in a small randomized trial of patients with IVIG-refractory KD [38]; in the latter study there was no significant difference in outcomes between infliximab and those treated with a second dose of IVIG. The package insert for this agent includes a warning that its use may predispose to serious infections such as TB and to lymphoma.

Even more limited published experience exists with respect to other therapies for IVIGresistant patients; cyclophosphamide with or without methotrexate has been used in a very small number of patients [39], and the same is true for plasma exchange.

\section{Management of KD beyond the acute stage}

After the acute stage of KD (when fever and inflammatory signs have resolved and C-reactive protein has normalized), patients should receive low-dose aspirin (3-5 mg/kg once daily) until their echocardiograms at 2 weeks and 6-8 weeks after illness onset are normal. To reduce the theoretical (and very remote at this low dose) risk of Reye syndrome in those taking low-dose aspirin, clopidogrel (Plavix ${ }^{\circledR}$ ) may be briefly substituted for aspirin in those who develop influenza or varicella. This agent also can be used in the rare child who is allergic to, or intolerant of, aspirin. If a baseline and the 2- and 6-8-week follow-up echocardiograms fail to reveal coronary abnormalities, subsequent echocardiograms are probably unnecessary [40], although a 6-12-month follow-up echocardiogram is performed at many centers [31]. 


\section{Long-term management of patients with KD}

The recommended long term management of individual KD patients is best considered by the degree of risk based upon their coronary artery status, as recommended by the American Heart Association [31].

\section{Risk level I: no evidence of coronary abnormalities at any time by}

echocardiograms-These patients have no need for aspirin or other antiplatelet medication beyond 2 and 3 months after the onset of KD or for restriction of physical activities. Only routine pediatric care with routine cardiovascular risk assessment is indicated.

Risk level II: transient coronary ectasia or dilatation-These patients with mild coronary changes that resolved by $6-8$ weeks should be treated with aspirin until the echocardiogram normalizes. There are no restrictions after 6-8 weeks; angiography is not indicated. Risk assessment and counseling are recommended at 3-5-year intervals.

Risk level III: isolated (solitary) small-to-medium size (3-6 $\mathrm{mm}$ ) aneurysm in one or more coronaries-These patients should receive daily low-dose aspirin (3-5 mg/kg daily) at least until regression is documented on annual echocardiographic follow-up. No restriction of activity is indicated for those under 11 years of age; in older patients, activity should be guided by the results of a biennial stress test or myocardial perfusion assay. Angiography should be performed if stenosis or ischemia is suggested.

\section{Risk level IV: those with one or more large $(>6 \mathrm{~mm}$ ) or giant $(>8 \mathrm{~mm}$ ) aneurysm} or multiple smaller or complex aneurysms without obstruction-These patients should receive long-term antiplatelet therapy (aspirin 3-5 mg/kg/day or clopidogrel $1 \mathrm{mg} / \mathrm{kg} /$ day up to adult dose of $75 \mathrm{mg} /$ day) indefinitely. In addition, anticoagulation with warfarin (target INR of 2.0-2.5) or with daily subcutaneous low-molecular-weight heparin is indicated to prevent thrombosis and ischemia. Cardiac evaluation with echocardiogram and ECG should be performed every 6 months, with stress testing approximately once per year. Angiography should be performed 6-12 months after the acute stage of KD and repeated if symptoms or stress tests suggest the presence of myocardial ischemia. Activity should be restricted on the basis of stress test results and level of anticoagulation, with strenuous activity discouraged.

Risk level V: those with coronary obstruction \&/or ischemia-These patients must be evaluated emergently for possible intervention that may include rotablader angioplasty, coronary artery bypass grafting and/or stent placement, arterioplasty and even cardiac transplantation [41-43]. The arterial wall in KD tends to be more fibrotic with more myointimal thickening than observed in adults with atherosclerotic coronary occlusion, which is more often associated with acute thrombosis. Nevertheless, fibrinolytic therapy with tissue plasminogen activator, urokinase or streptokinase is indicated for acute coronary occlusion in KD when coronary thrombosis is suspected, even though the pathophysiology is somewhat different from that of adults in whom these protocols are generally developed [31]. Abciximab, a glycoprotein $\mathrm{IIb} / \mathrm{III}$ inhibitor, has been used in a handful of KD patients with acute coronary thrombosis [44]. Balloon angioplasty procedures in KD have been associated with high rates of recurrent stenosis or neoaneurysms related to the very high balloon pressures required and should generally be avoided [45]. A recent publication from Japan has documented the 25-year outcomes of coronary artery bypass surgery in $114 \mathrm{KD}$ children and adolescents from 1 to 19 years of age, showing that internal thoracic arterial grafts are optimal and that 20- and 25-year survival rates were 95\% [46]. 


\section{Expert commentary \& five-year view}

The following model of KD pathogenesis incorporates clinical, epidemiologic, immunologic and pathologic features of KD. KD is probably the result of infection with a ubiquitous infectious agent, most probably a single virus or a group of closely related viruses, which results in asymptomatic infection in most individuals but leads to KD only in a very small subset of genetically predisposed individuals. There is no precedent for a febrile systemic illness of childhood with such strikingly consistent clinical features as KD to be the result of infection with multiple disparate infectious agents. In the past, such claims were made for polio, AIDS, roseola and fifth disease prior to identification of their causative agents, all of which were determined to be single infectious agents or a group of very closely related agents.

In a child with KD, the infectious agent probably enters through the respiratory tract, infecting ciliated bronchial epithelium, and both innate and adaptive immune responses ensue, initially in the respiratory tract, with B lymphocytes switching to IgA lymphocytes. The agent enters a small subset of macrophages traveling through the bronchial submucosa and travels within the macrophage through the circulation. As these infected macrophages traverse tissues as part of normal immune surveillance, the agent is able to infect its target tissues such as the coronary artery. Antigen is processed by local lymphoid tissues, and CD8 T lymphocytes and IgA B lymphocytes with a good match for the antigen are expanded. These immune cells leave the lymphoid tissue, traveling back to infected tissues and contributing to the inflammatory response within the tissues. Additional macrophages and some neutrophils also enter inflamed tissues. Under the influence of local cytokines produced by macrophages in the tissues, $\operatorname{IgA~B}$ lymphocytes terminally differentiate into plasma cells and produce antigen-specific antibodies locally. CD8 T lymphocytes act to eradicate infected cells by cytotoxic mechanisms. Within the arterial wall, the production of matrix metalloproteinases and other enzymes by macrophages results in destruction of collagen and elastin fibers. The wall can lose its structural integrity and dilate or balloon, forming an aneurysm. The immune response is ultimately successful in controlling the pathogen, particularly if IVIG is given, but damage to the coronary arteries may have already occurred.

If $\mathrm{KD}$ is the result of infection with a ubiquitous infectious agent as described here, immunoglobulin pooled from adult blood donors should contain antibody to the infectious agent. This suggests a mechanism of action of IVIG in KD. A mechanism of antibodydependent cellular cytotoxicity, in which immune IgG binds infected cells through its antibodybinding (Fab) end and effector cells through its antibody-tail $(\mathrm{Fc})$ end, leading to destruction of the infected cells, could explain the dramatic efficacy of IVIG in KD. This mechanism appears to account for the similar dramatic clinical response to immune $\gamma$-globulin in Argentine hemorrhagic fever, an arenavirus infection of humans [47-49].

Over the next 5 years, we anticipate identification of additional genes influencing susceptibility to KD and to the development of coronary artery aneurysms. Expression profiles of genes involved in KD pathogenesis will be determined in the peripheral blood and tissues of KD patients, which is likely to provide new therapeutic approaches. Use of bioinformatics analysis of DNA and RNA sequences from KD tissues may allow for identification of the elusive etiologic agent of KD. This would truly revolutionize the field and allow for the development of a diagnostic test, improved therapies and prevention of this potentially devastating illness of childhood.

\section{Key issues}


- Kawasaki disease (KD), the most prevalent cause of acquired heart disease in children in industrialized nations, can result in coronary artery aneurysms, myocardial infarction and sudden death.

- Clinical and epidemiologic features of the illness suggest that the cause is a common infectious agent that results in asymptomatic infection in most individuals and $\mathrm{KD}$ in a subset of genetically predisposed children.

- $\mathrm{KD}$ is a systemic inflammatory process of young childhood, involving multiple organs and tissues. Inflammation of the coronary arteries is the most clinically significant aspect of this process.

- An oligoclonal, antigen-driven IgA immune response is characteristic of KD. Synthetic versions of oligoclonal $\operatorname{IgA}$ antibodies from KD patients bind to cytoplasmic inclusion bodies in KD ciliated bronchial epithelium and in macrophages in inflamed tissues. Thus, IgA antibodies in KD appear to target a microbial antigen, not an autoantigen.

- Cytoplasmic inclusion bodies in KD tissues appear to contain proteins and RNA that most likely derive from the etiologic agent.

- Intravenous immunoglobulin (IVIG) and aspirin therapy, when administered in the first 10 days of illness, reduces the prevalence of coronary artery abnormalities in acute $\mathrm{KD}$ from $25-30 \%$ in untreated patients to $3-5 \%$ in treated patients.

- Approximately $10-15 \%$ of KD children do not respond to a first dose of IVIG with aspirin; a second dose of IVIG is often effective in these patients.

- Patients who do not respond to two doses of IVIG with aspirin may respond to intravenous methylprednisolone daily for 3 days, a third dose of IVIG or a single dose of infliximab.

- Identification of the causative agent of KD would be the single best means of improving diagnosis and therapy and allowing prevention of the illness.

\section{References}

Papers of special note have been highlighted as:

- of interest

•• of considerable interest

1 . Amano S, Hazama F, Kubagawa H, Tasaka K, Haebara H, Hamashima Y. General pathology of Kawasaki disease. On the morphological alterations corresponding to the clinical manifestations. Acta Pathol Jpn 1980;30(5):681-694. Comprehensive autopsy study of 37 Japanese children with fatal kawasaki disease (KD), detailing the high incidence of inflammatory lesions in many organs and tissues. [PubMed: 7446109]

2•. Rowley AH, Baker SC, Orenstein JM, Shulman ST. Searching for the cause of Kawasaki disease cytoplasmic inclusion bodies provide new insight. Nat Rev Microbiol 2008;6(5):394-401. Review of etiologic, pathologic and immunologic studies in KD, including the discovery that viral-like cytoplasmic inclusion bodies are present in KD tissues, and proposing a model of KD pathogenesis based upon available data. [PubMed: 18364728]

3. Brown TJ, Crawford SE, Cornwall ML, Garcia F, Shulman ST, Rowley AH. CD8 T lymphocytes and macrophages infiltrate coronary artery aneurysms in acute Kawasaki disease. J Infect Dis 2001;184 (7):940-943. [PubMed: 11528596]

4. Rowley AH, Eckerley CA, Jack HM, Shulman ST, Baker SC. IgA plasma cells in vascular tissue of patients with Kawasaki syndrome. J Immunol 1997;159(12):5946-5955. [PubMed: 9550392] 
5. Rowley AH, Shulman ST, Mask CA, et al. IgA plasma cell infiltration of proximal respiratory tract, pancreas, kidney, and coronary artery in acute Kawasaki disease. J Infect Dis 2000;182(4):1183-1191. [PubMed: 10979916]

6. Yilmaz A, Rowley A, Schulte DJ, et al. Activated myeloid dendritic cells accumulate and co-localize with $\mathrm{CD} 3^{+} \mathrm{T}$ cells in coronary artery lesions in patients with Kawasaki disease. Exp Mol Pathol 2007;83(1):93-103. [PubMed: 17335804]

7. Hirao J, Hibi S, Andoh T, Ichimura T. High levels of circulating interleukin-4 and interleukin-10 in Kawasaki disease. Int Arch Allergy Immunol 1997;112(2):152-156. [PubMed: 9030095]

8. Lin CY, Lin CC, Hwang B, Chiang B. Serial changes of serum interleukin-6, interleukin-8, and tumor necrosis factor $\alpha$ among patients with Kawasaki disease. J Pediatr 1992;121(6):924-926. [PubMed: 1447658]

9. Maury CP, Salo E, Pelkonen P. Elevated circulating tumor necrosis factor- $\alpha$ in patients with Kawasaki disease. J Lab Clin Med 1989;113(5):651-654. [PubMed: 2715685]

10. Gavin PJ, Crawford SE, Shulman ST, Garcia FL, Rowley AH. Systemic arterial expression of matrix metalloproteinases 2 and 9 in acute Kawasaki disease. Arterioscler Thromb Vasc Biol 2003;23(4): 576-581. [PubMed: 12692003]

11. Yasukawa K, Terai M, Shulman ST, et al. Systemic production of vascular endothelial growth factor and FMS-like tyrosine kinase-1 receptor in acute Kawasaki disease. Circulation 2002;105(6):766769. [PubMed: 11839635]

12. Freeman AF, Crawford SE, Cornwall ML, Garcia FL, Shulman ST, Rowley AH. Angiogenesis in fatal acute Kawasaki disease coronary artery and myocardium. Pediatr Cardiol 2005;26(5):578-584. [PubMed: 16132289]

13. Miura M, Garcia FL, Crawford SE, Rowley AH. Cell adhesion molecule expression in coronary artery aneurysms in acute Kawasaki disease. Pediatr Infect Dis J 2004;23(10):931-936. [PubMed: 15602193]

14. Rowley AH, Shulman ST, Spike BT, Mask CA, Baker SC. Oligoclonal IgA response in the vascular wall in acute Kawasaki disease. J Immunol 2001;166(2):1334-1343. [PubMed: 11145718]

15. Rowley AH, Baker SC, Shulman ST, et al. Detection of antigen in bronchial epithelium and macrophages in acute Kawasaki disease by use of synthetic antibody. J Infect Dis 2004;190(4):856865. [PubMed: 15272416]

16. Rowley AH, Shulman ST, Garcia FL, et al. Cloning the arterial IgA antibody response during acute Kawasaki disease. J Immunol 2005;175(12):8386-8391. [PubMed: 16339580]

17••. Rowley AH, Baker SC, Shulman ST, et al. Cytoplasmic inclusion bodies are detected by synthetic antibody in ciliated bronchial epithelium during acute Kawasaki disease. J Infect Dis 2005;192(10): 1757-1766. Light and electron microscopic study of cytoplasmic inclusion bodies detected by KD synthetic antibody, showing that they are consistent with aggregates of viral proteins and nucleic acids. [PubMed: 16235174]

18• Rowley AH, Baker SC, Shulman ST, et al. RNA-containing cytoplasmic inclusion bodies in ciliated bronchial epithelium months to years after acute Kawasaki disease. PLoS ONE 2008;3(2):e1582.

Study demonstrating the presence of RNA-containing cytoplasmic inclusion bodies in $85 \%$ of acute and late-stage KD fatalities, and in $25 \%$ of adult controls, consistent with the hypothesis that KD is the result of infection with a previously unidentified, ubiquitous, persistent RNA virus. [PubMed: 18270572]

19. Holman RC, Curns AT, Belay ED, Steiner CA, Schonberger LB. Kawasaki syndrome hospitalizations in the United States, 1997 and 2000. Pediatrics 2003;112(3 Pt 1):495-501. [PubMed: 12949272]

20. Nakamura Y, Yashiro M, Uehara R, Oki I, Watanabe M, Yanagawa H. Epidemiologic features of Kawasaki disease in Japan: results from the nationwide survey in 2005-2006. J Epidemiol 2008;18 (4):167-172. [PubMed: 18635901]

21 . Onouchi Y. Molecular genetics of Kawasaki disease. Pediatr Res 2009;65(5 Pt 2):46R-54R. Summary of genetic studies of KD, including a description of newer, more powerful genetic methods to identify the multiple genes probably involved in predisposition to KD.

22. Onouchi Y, Tamari M, Takahashi A, et al. A genomewide linkage analysis of Kawasaki disease: evidence for linkage to chromosome 12. J Hum Genet 2007;52(2):179-190. [PubMed: 17160344] 
23. Onouchi Y, Gunji T, Burns JC, et al. ITPKC functional polymorphism associated with Kawasaki disease susceptibility and formation of coronary artery aneurysms. Nat Genet 2008;40(1):35-42. [PubMed: 18084290]

24. Burgner D, Davila S, Breunis WB, et al. A genome-wide association study identifies novel and functionally related susceptibility Loci for Kawasaki disease. PLoS Genet 2009;5(1):e1000319. [PubMed: 19132087]

25. Newburger JW, Takahashi M, Beiser AS, et al. A single intravenous infusion of $\gamma$ globulin as compared with four infusions in the treatment of acute Kawasaki syndrome. N Engl J Med 1991;324 (23):1633-1639. [PubMed: 1709446]

26••. Newburger JW, Takahashi M, Burns JC, et al. The treatment of Kawasaki syndrome with intravenous $\gamma$ globulin. N Engl J Med 1986;315(6):341-347. Classic multicenter treatment trial that showed a single large ( $2 \mathrm{~g} / \mathrm{kg}$ ) dose of intravenous immunoglobulin (IVIG) to be superior to four once-daily infusions in acute $\mathrm{KD}$, with lower rates of development of coronary abnormalities and prompter normalization of inflammatory markers. [PubMed: 2426590]

27. Tse SM, Silverman ED, McCrindle BW, Yeung RS. Early treatment with intravenous immunoglobulin in patients with Kawasaki disease. J Pediatr 2002;140(4):450-455. [PubMed: 12006960]

28. Muta H, Ishii M, Egami K, et al. Early intravenous $\gamma$-globulin treatment for Kawasaki disease: the nationwide surveys in Japan. J Pediatr 2004;144(4):496-499. [PubMed: 15069399]

29. Zhang T, Yanagawa H, Oki I, Nakamura Y. Factors relating to the cardiac sequelae of Kawasaki disease one month after initial onset. Acta Paediatr 2002;91(5):517-520. [PubMed: 12113319]

30. Terai M, Shulman ST. Prevalence of coronary artery abnormalities in Kawasaki disease is highly dependent on $\gamma$ globulin dose but independent of salicylate dose. J Pediatr 1997;131(6):888-893. [PubMed: 9427895]

31••. Newburger JW, Takahashi M, Gerber MA, et al. Diagnosis, treatment, and long-term management of Kawasaki disease: a statement for health professionals from the Committee on Rheumatic Fever, Endocarditis, and Kawasaki Disease, Council on Cardiovascular Disease in the Young, American Heart Association. Pediatrics 2004;114(6):1708-1733. Comprehensive statement from the appropriate committee of the American Heart Association that details diagnosis, treatment and longterm management principles. [PubMed: 15574639]

32. Jibiki T, Terai M, Kurosaki T, et al. Efficacy of intravenous immune globulin therapy combined with dexamethasone for the initial treatment of acute Kawasaki disease. Eur J Pediatr 2004;163(4-5):229_ 233. [PubMed: 14963702]

33. Inoue Y, Okada Y, Shinohara M, et al. A multicenter prospective randomized trial of corticosteroids in primary therapy for Kawasaki disease: clinical course and coronary artery outcome. J Pediatr 2006;149(3):336-341. [PubMed: 16939743]

34- Newburger JW, Sleeper LA, McCrindle BW, et al. Randomized trial of pulsed corticosteroid therapy for primary treatment of Kawasaki disease. N Engl J Med 2007;356(7):663-675. This very well done clinical trial did not show a clear benefit of adding a single dose of intravenous methylpredisone to therapy with $2 \mathrm{~g} / \mathrm{kg}$ IVIG and high-dose aspirin for acute KD. [PubMed: 17301297]

35. Freeman AF, Shulman ST. Refractory Kawasaki disease. Pediatr Infect Dis J 2004;23(5):463-464. [PubMed: 15131473]

36. Sundel RP, Burns JC, Baker A, Beiser AS, Newburger JW. $\gamma$ globulin re-treatment in Kawasaki disease. J Pediatr 1993;123(4):657-659. [PubMed: 8410524]

37. Burns JC, Mason WH, Hauger SB, et al. Infliximab treatment for refractory Kawasaki syndrome. J Pediatr 2005;146(5):662-667. [PubMed: 15870671]

38. Burns JC, Best BM, Mejias A, et al. Infliximab treatment of intravenous immunoglobulin-resistant Kawasaki disease. J Pediatr 2008;153(6):833-838. [PubMed: 18672254]

39. Wallace CA, French JW, Kahn SJ, Sherry DD. Initial intravenous $\gamma$-globulin treatment failure in Kawasaki disease. Pediatrics 2000;105(6):E78. [PubMed: 10835091]

40. McMorrow Tuohy AM, Tani LY, Cetta F, et al. How many echocardiograms are necessary for followup evaluation of patients with Kawasaki disease? Am J Cardiol 2001;88(3):328-330. [PubMed: 11472722] 
41. Checchia PA, Pahl E, Shaddy RE, Shulman ST. Cardiac transplantation for Kawasaki disease. Pediatrics 1997;100(4):695-699. [PubMed: 9310527]

42. Gotteiner N, Mavroudis C, Backer CL, et al. Coronary artery bypass grafting for Kawasaki disease. Pediatr Cardiol 2002;23(1):62-67. [PubMed: 11922511]

43. Ishii M, Ueno T, Akagi T, et al. Guidelines for catheter intervention in coronary artery lesion in Kawasaki disease. Pediatr Int 2001;43(5):558-562. [PubMed: 11737728]

44. Williams RV, Wilke VM, Tani LY, Minich LL. Does Abciximab enhance regression of coronary aneurysms resulting from Kawasaki disease? Pediatrics 2002;109(1):E4. [PubMed: 11773572]

45. Sugimura T, Yokoi H, Sato N, et al. Interventional treatment for children with severe coronary artery stenosis with calcification after long-term Kawasaki disease. Circulation 1997;96(11):3928-3933. [PubMed: 9403617]

46••. Kitamura S, Tsuda E, Kobayashi J, et al. Twenty-five-year outcome of pediatric coronary artery bypass surgery for Kawasaki disease. Circulation 2009;120(1):60-68. This unique Japanese study reports long- term (median follow up: 19 years) outcomes for 114 children and adolescents who underwent coronary bypass surgery for KD complications. The 25 -year survival rate was $95 \%$, cardiac event-free rates at 20 and 25 years were $67 \%$ and $60 \%$, respectively, and over all 20-year graft potency rate was $87 \%$ for internal thoracic artery and $44 \%$ for saphenous vein grafts. [PubMed: 19546384]

47. Maiztegui JI, Fernandez NJ, de Damilano AJ. Efficacy of immune plasma in treatment of Argentine haemorrhagic fever and association between treatment and a late neurological syndrome. Lancet 1979;2(8154):1216-1217. [PubMed: 92624]

48. Enria DA, Briggiler AM, Fernandez NJ, Levis SC, Maiztegui JI. Importance of dose of neutralising antibodies in treatment of Argentine haemorrhagic fever with immune plasma. Lancet 1984;2(8397): 255-256. [PubMed: 6146809]

49. Kenyon RH, Condie RM, Jahrling PB, Peters CJ. Protection of guinea pigs against experimental Argentine hemorrhagic fever by purified human IgG: importance of elimination of infected cells. Microb Pathog 1990;9(4):219-226. [PubMed: 1965845] 